\title{
HUMANIZAÇÃO: PERCEPÇÕES DOS ESTUDANTES DE FISIOTERAPIA E USUÁRIOS
}

\author{
Cíntia Carla Matos Barros RIGONATTO ${ }^{1}$ \\ Magali Aparecida Alves de MORAES ${ }^{2}$
}

\begin{abstract}
${ }^{1}$ Mestranda do Programa de Mestrado Profissional em "Ensino em Saúde”, FAMEMA Marília SP Brasil.

${ }^{1}$ Rua Souza Naves 2072, Parque São Paulo, Cep 85803-770 Cascavel PR. crigonatto@ hotmail.com

${ }^{2}$ Docente do Mestrado Profissional, Doutora em Educação, Faculdade de Medicina de Marília (Famema) - Marília SP - Brasil.
\end{abstract}

Recebido em: 29/05/2014 - Aprovado em: 17/09/2014 - Disponibilizado em: 15/12/2014

\begin{abstract}
RESUMO
O objetivo deste estudo é analisar as percepções dos estudantes de fisioterapia e dos usuários ou acompanhantes quanto ao atendimento prestado com abordagem na humanização. Pesquisa qualitativa. Os participantes foram estudantes de fisioterapia que faziam estágio em um hospital público, os usuários internados que recebiam cuidados de fisioterapia ou seus acompanhantes. Para a coleta de dados, foram realizadas entrevistas, com roteiros de perguntas semiestruturadas. Os dados coletados foram compilados, analisados e categorizados em três categorias: 1) Expectativas dos estudantes frente ao relacionamento com o paciente hospitalizado; 2) Atendimento humanizado; 3) Humanização na graduação. É possível concluir que o estudo da humanização é um assunto amplo; que os usuários e acompanhantes veem o atendimento recebido com satisfação; que o estudante apesar de ter carência de conhecimentos científicos sobre o tema, demonstra interesse pelo assunto e que, na graduação, pode-se enraizar valores de respeito à vida humana. Enfim a instituição formadora é responsável também por preparar esses futuros profissionais em uma nova cultura de atendimento à saúde.
\end{abstract}

Palavras-chave: Humanização da assistência. Estudantes. Fisioterapia. Pacientes internados.

\begin{abstract}
The aim is to analyze the perceptions of physiotherapy students and the users or carers regarding the care provided with the humanization approach. This is a qualitative research. Senior physiotherapy students which were in internship at a public hospital, inpatients who received physiotherapy care as well as their carers were the participants of this study. Interviews with semi-structured questions, recorded with a tape recorder were used for data collection. The collected data was compiled, analyzed and categorized into three broad categories: 1) Students' expectations through the relationship with the hospitalized patient; 2) Humanized care and 3) Humanization during major. From the data obtained It can be concluded that humanization is a wide subject; the users and caregivers see the care received with satisfaction; despite having a lack of scientific knowledge on the subject, the students show interest in it and during major, it may be rooted some values concerning respect for human life. Finally, the educational institution is also responsible for preparing these future professionals in a new culture of health care.
\end{abstract}

Key-words: Humanization of assistance. Students. Physical therapy specialty. Inpatients.

\section{INTRODUÇÃO}

No Brasil, a fisioterapia apareceu por volta de 1950, como curso técnico, acessível aos estudantes com segundo grau completo, embora não existisse estrutura curricular que direcionasse a formação desses profissionais. (SANCHES; MARQUES, 1994)
Com relação às propostas curriculares existentes na história da fisioterapia, sabe-se que a primeira delas foi tornada pública em 1964, quando se estabeleceu um mínimo de conteúdos, compostos de matérias comuns e matérias específicas. (BRASIL, 1967) E a segunda, em 1983, onde estabelecendo-se um 
currículo com 4 ciclos (BRASIL, 1968). O ciclo de formação geral traz, pela primeira vez a discussão do homem e da sociedade, dando ao curso um cunho mais humanístico.

Em 2001, são aprovadas as Diretrizes Curriculares Nacionais do curso de graduação em fisioterapia que está em vigor até hoje. Seu conteúdo deve abranger o "estudo do homem e de suas reações sociais, do processo saúde-doença nas múltiplas determinações, contemplando a integração dos aspectos psicossociais, culturais, filosóficos, antropológicos e epidemiológicos norteados pelos princípios éticos. Também deverá contemplar conhecimentos relativos às políticas de saúde, educação, trabalho e administração", (BRASIL, 2001) dentre elas a Política Nacional de Humanização (PNH).

Atualmente, o termo humanização é aplicado às situações em que se valoriza o cuidado, em suas dimensões técnicas e científicas; se reconhecem os direitos do paciente, respeitando sua individualidade, sua dignidade, sua autonomia, e sua subjetividade, sem que se esqueça do profissional também como ser humano. (BRASIL 2001)

Neste estudo, o termo humanização nas práticas de saúde foi entendido como o encontro de sujeitos no ato e pelo ato de cuidar, o que está em consonância com o Ministério da Saúde, baseando-se nos "valores de autonomia e protagonismo dos sujeitos, de co-responsabilidade entre eles, por meio do estabelecimento de vínculos solidários, da construção de redes de cooperação e da participação coletiva no processo de gestão". (BRASIL, 2004)

Para isso, é necessária à inclusão nos currículos, de conteúdos que abordem o ser humano e as suas relações.

Considerando esse contexto e tendo em vista o crescente interesse pela temática da humanização e a necessidade de qualificar a intervenção em saúde, buscamos desenvolver um estudo para avaliar quais as percepções dos estudantes de fisioterapia e dos usuários por eles atendidos, quanto ao atendimento prestado com abordagem da temática da humanização.

\section{MÉTODO}

Trata-se de uma pesquisa de campo com abordagem qualitativa.

Este estudo foi desenvolvido em um hospital público estadual, em uma cidade do interior do Estado de São Paulo.

Os participantes da pesquisa foram 20 estudantes, 5 usuários e 3 acompanhantes.

Para garantir o sigilo dos participantes optou-se por identificá-los por nomes fictícios com as iniciais E para estudantes, U para usuários e A para acompanhantes.

Os estudantes cursam o quarto ano do curso de fisioterapia de uma instituição particular de ensino. Conforme caracterizados no quadro a seguir: 
Tabela 1 - Distribuição dos dados sociodemográficos dos estudantes da amostra estudada. Marília-SP 2014

\section{\begin{tabular}{l|l|l}
\hline CARACTERÍSTICAS & $\mathbf{N}$ & $\%$ \\
\hline
\end{tabular}} GÊNERO

FAIXA ETÁRIA

$\begin{array}{lll}\text { Masculino } & 16 & 80 \\ \text { Feminino } & 4 & 20\end{array}$

$\begin{array}{lll}20-25 & 15 & 75 \\ 26-30 & 4 & 20 \\ >30 & 1 & 5\end{array}$

ESTADO CIVIL

\begin{tabular}{lll} 
Casado & 4 & 20 \\
Solteiro & 16 & 80 \\
\hline
\end{tabular}

Fonte: próprio autor

Já os usuários são pacientes internados nas enfermarias de pacientes adultos e os acompanhantes destes na internação, que só participaram em caso de impossibilidade de comunicação dos usuários. Conforme caracterizados no quadro a seguir:

Quadro 1 - Distribuição dos dados sociodemográficos dos usuários e acompanhantes da amostra estudada. Marília-SP 2014

\begin{tabular}{|l|l|l|l|l|}
\hline Nome & Gênero & Idade & $\begin{array}{l}\text { Escolaridad } \\
\text { e }\end{array}$ & $\begin{array}{l}\text { Estado } \\
\text { civil }\end{array}$ \\
\hline Ulisses & M & 27 & $\begin{array}{l}\text { Ensino } \\
\text { fundamental } \\
\text { incompleto }\end{array}$ & Amigado \\
\hline Úrsula & F & 52 & $\begin{array}{l}\text { Ensino } \\
\text { fundamental } \\
\text { completo }\end{array}$ & Casada \\
\hline Uda & F & 24 & $\begin{array}{l}\text { Ensino } \\
\text { superior } \\
\text { incompleto }\end{array}$ & Solteira \\
\hline Uiara & F & 55 & $\begin{array}{l}\text { Ensino } \\
\text { médio } \\
\text { incompleto }\end{array}$ & Solteira \\
\hline $\begin{array}{l}\text { Umbelin } \\
\text { a }\end{array}$ & F & 55 & $\begin{array}{l}\text { Ensino } \\
\text { fundamental } \\
\text { incompleto }\end{array}$ & Divorciada \\
\hline Alice & F & 47 & $\begin{array}{l}\text { Ensino } \\
\text { médio } \\
\text { completo }\end{array}$ & Casada \\
\hline $\begin{array}{l}\text { Amand } \\
\text { a }\end{array}$ & F & 31 & $\begin{array}{l}\text { Ensino } \\
\text { médio } \\
\text { completo }\end{array}$ & Casada \\
\hline Andréia & F & 35 & $\begin{array}{l}\text { Ensino } \\
\text { médio } \\
\text { completo }\end{array}$ & Casada \\
\hline Fonte: & Frio autor & & \\
\hline
\end{tabular}

Fonte: próprio autor
A participação tanto dos estudantes de fisioterapia como dos usuários ou dos acompanhantes foi voluntária.

Esta pesquisa, foi submetida à apreciação do Comitê de Ética em pesquisa com seres humanos da Faculdade de Medicina de Marília (Famema), com base na resolução $n^{\circ}$ 466/12 do Conselho Nacional de Saúde, sendo autorizada sob o parecer número 206.606, aprovado em 27/02/2013.

\section{Coleta de dados}

A coleta de dados foi realizada em quatro momentos no ano de 2013, conforme horário de estágio dos estudantes e ao completarem 30 dias de vivência no ambiente de estágio. Neste período, também os usuários ou acompanhantes foram entrevistados.

\subsubsection{Instrumentos}

Foi utilizada a entrevista como instrumento de coleta de dados.

Foram elaborados dois roteiros de entrevista semiestruturados, um para ser realizada com os estudantes e outro para ser realizado com os usuários ou acompanhantes. As entrevistas com os participantes foram registradas com o uso do gravador.

\section{Análise dos dados}

Os dados foram tratados e relacionados entre si, por meio da análise de conteúdo, modalidade temática, com abordagem qualitativa. (GOMES, 2009)

Diante das informações obtidas pela leitura e análise das transcrições, foram sistematizados os dados, de acordo com cada questão dos roteiros das entrevistas, 
identificando-se temas específicos, que constituíram as subcategorias.

Pelo do agrupamento dos dados em comum das subcategorias, foi possível definir as categorias.

\section{RESULTADOS E DISCUSSÃO}

Após análise dos dados identificamos três categorias com suas respectivas subcategorias a saber:

1) Expectativas dos estudantes frente ao relacionamento com o paciente hospitalizado: reações emocionais; bioética; competência profissional e relação fisioterapeuta/paciente.

\section{2) Atendimento humanizado:} singularidade; tecnologias em saúde e ambiência; compreensão biopsicossocial do paciente; respeito; empatia; equipe de saúde e qualidade no atendimento.

\section{3) Humanização na graduação:} inserção do tema no currículo; definição de humanização e importância para a formação.

As categorias temáticas estão apresentadas e analisadas a seguir. Expectativas dos estudantes frente ao relacionamento com 0 paciente hospitalizado

A entrada brusca dos estudantes numa situação desconhecida, hospitalar e que envolve o adoecer é um fator desencadeante de reações emocionais, como medo, apreensão, indecisão e insegurança, observado nas falas dos estudantes entrevistados:
[...] esperava encontrar pessoas bem debilitadas, bem tristes [...] medo de ver alguma morte [...] (Edite)

[...] a minha maior preocupação [...] é a gravidade do caso [...] (Eduarda).

Esses sentimentos relatados são comuns, revelam os aspectos humanos do estudante e isso deve ser considerado para humanização da assistência. Como relata NOGUEIRA-MARTINS 2004, as angústias ligadas ao adoecer são parte integrante dessa relação, que é o campo dinâmico que se estabelece entre o cliente e aquele que o assiste, onde surgem as angústias básicas profundas e intensas que se desenvolvem no vínculo estabelecido.

A necessidade de superar tais ansiedades, pode potencializar a assistência, nesse momento importante para a formação do estudante que é o estágio supervisionado. Aproveita-se o cenário hospitalar para resgatar conhecimentos técnicos apreendidos e conseguir exercer aquilo que faz parte de sua competência profissional.

Segundo as diretrizes curriculares, os estudantes dos cursos de graduação em saúde devem "aprender a aprender, o que engloba aprender a ser, aprender a fazer, aprender a viver juntos e aprender a conhecer, garantindo sua capacitação, como profissionais, com autonomia e discernimento para assegurar a integralidade da atenção, a qualidade e a humanização do atendimento prestado aos indivíduos, às famílias e às comunidades". (BRASIL, 2001) 
Observa-se abaixo pelos depoimentos dos estudante entrevistados, que sua preocupação se atém ao aprender a fazer:

[...] Focar no que ele precisa, no tratamento da fisioterapia [...] tentar passar para o paciente tudo o que a gente sabe [...] (Elda)

Associados ao saber fazer observa-se nas falas dos estudantes dois princípios da bioética que é a não maleficência, que além de preocupar-se com o fazer, preocupa-se em não cometer o mal:

[...] fico preocupada com meu atendimento, porque qualquer coisinha que eu fizer errado eu posso causar um efeito muito grande nele [...] (Eduarda)

E o outro princípio é a beneficência que apesar desse contexto de circunstâncias tão diversas e conflituosas que envolvem o estágio do estudante de fisioterapia em hospital, observa-se a intenção do estudante em querer ajudar o paciente a melhorar. Respeitando esse primeiro princípio da bioética, ou seja, fazer o bem ao paciente pode ser observado na fala abaixo:

[...] atender o paciente de forma que possa tá ajudando ele sair de lá bom [...] para que ele possa ter uma melhor qualidade de vida, para que ele possa sair de lá logo, prevenir que ele tenha complicações [...] (Edna)

Sabe-se que o estudante de fisioterapia precisa do contato direto com o paciente para realização de suas técnicas, desenvolvendo por esse contato uma relação fisioterapeutapaciente especial, que segundo NATIONS E GOMES 2007 representa o cerne do cuidado humanizado.

[...] ele me tratar bem e receber bem o tratamento [...] (Élcio)

[...] ter um bom relacionamento com o paciente $[\ldots]$ (...́der)
Neste sentido, se o supervisor de estágio reconhecer as expectativas dos estudantes e acolhê-las poderá contribuir para uma relação humanizada na formação destes estudantes.

\section{Atendimento humanizado}

O Programa Nacional de Humanização da Assistência Hospitalar (PNHAH) visa mudar o padrão de assistência ao usuário. Propõe um processo de mudança na cultura do atendimento, melhorando a qualidade e a eficácia dos serviços, tendo como objetivo, o aprimoramento das relações entre todos os atores inseridos no cenário hospitalar.

No campo das relações humanas, as quais caracterizam qualquer atendimento de saúde, é essencial agregar eficiência técnica e científica aorespeito pela singularidade das necessidades do usuário e do profissional. Assim como preconiza no PNHAH a singularidade foi salientada como importante pelos entrevistados estudantes, usuários e acompanhantes:

[...] é olhar para as necessidades dele, ver o que ele tá precisando para aquele momento e tentar suprir essas necessidades porque é individual, depende de cada caso [...] (Eduarda)

[...] porque ele pode atender paciente com a mesma doença, mas tem que se dedicar a cada um diferente, o paciente muda muito um pelo outro [...] (Uiara)

Além das relações humanas, as tecnologias em saúde e a questão da ambiência revelaram-se nas falas de um estudante. As tecnologias em saúde se dividem em dura, leve-dura e leve. A dura diz respeito às várias ferramentas que usamos 
(raio $\mathrm{x}$, instrumentos para fazer exames de laboratório, instrumentos para examinar o paciente, fichários para anotar dados do usuário). (MERHY, 1999)

Já a ambiência em saúde, segundo a PNH "refere-se ao tratamento dado ao espaço físico entendido como espaço social, profissional e de relações interpessoais que deve proporcionar atenção acolhedora, resolutiva e humana". (BRASIL, 2006) Segue abaixo a fala do estudante sobre tecnologias em saúde e ambiência:

[...] conter condições básicas, a higiene, aqui no caso equipamentos para o profissional trabalhar [...] o local, o ambiente, se tivesse a possibilidade de sair um pouco desse padrãozão de hospital [...] alguma cor alguma coisa que faça lembrar da própria casa” [...] (Estela)

Os hospitais, em sua maioria, estão organizados para tratar apenas das doenças das pessoas, mas o usuário mesmo estando internado, mantém sua característica humana de totalidade. Ele precisa manter-se higienizado, estar em ambiente limpo e confortável, comer, dormir, além de relacionar-se com outras pessoas e ser nutrido afetivamente.

Cada pessoa deve ser vista de maneira holística, como um ser biopsicossocial, considerando e respeitando suas necessidades. Assim a humanização apresenta-se como estratégia que possibilita a atenção integral, equânime com responsabilização e vínculo CAETANO; CRUZ; SILVA; LEITE 2012 concluem pelas falas das entrevistadas, que a visão estritamente fisiopatológica, baseada no modelo biomédico não oferece resultados satisfatórios e eficazes na assistência fisioterapêutica. É necessária a implementação de práticas que priorizem a visão holística e integrada do paciente. Tal necessidade de compreensão biopsicossocial do paciente é referida em nosso estudo tanto pelos estudantes como pelos usuários e acompanhantes:

[...] Ah é ser tratado como um todo né não só com o que ele veio, mas pensando que ele é uma pessoa [...] (Elenice)

[...] ao meu ver ele tem que atender o paciente como um todo, não é só focalizar a fisioterapia [...] (Umbelina)

Trata-se de um ser e fazer que se inspira numa disposição de abertura e de respeito ao outro.considerando-o como um ser autônomo e digno.

Embora o conceito de respeito seja bastante amplo, pode-se pontuar que, ao agir de forma a considerar a individualidade e subjetividade do paciente, tratando-o com estima, atenção, consideração e deferência, o profissional estará agindo de forma respeitosa e, portanto, oferecendo cuidados mais integrais e humanizados. (HOUAISS; VILLAR; FRANCO, 2009)

Respeitar envolve ouvir o que o outro tem a dizer, interpretando o que ouvimos, tendo compaixão, sendo tolerante, honesto e atencioso. (FERNANDES; PEEIRA, 2005)

Nos depoimentos a seguir, pode ser observado que o respeito é necessário para o atendimento humanizado:

[...] gostaria que as pessoas fizessem por mim, por exemplo, de me tratar com carinho, 
de me manusear com cuidado de ter respeito com minha pessoa [...] (Elen)

[...] são humanas [...] [...] porque vocês falam com ele [...] [...] não sou estudada e vocês profissionais falam comigo [...] de uma forma que eu entendo, vocês falam que vão fazer isso, vão fazer aquilo e fazem bem feito [...] (Alice)

Assim, para cuidar de forma humanizada, o profissional da saúde deve ser capaz de entender a si próprio e ao outro. Nesse contexto, respeitar o paciente é componente essencial no tocante a cuidados humanizados. (PESSIN, 2002) (PESSINI; BERTACHINI, 2004)

Para o paciente perceber laços de empatia é importante, e isso acontece quando o profissional consegue se colocar no lugar do outro e, a partir daí, desenvolver a vontade em ajudar.

HOWARD 1975 apresenta a empatia e o afeto como a dimensão psicológica nos fatores de humanização, sendo a empatia um dos comportamentos potencialmente humanizadores do cuidado e o afeto como envolvimento emocional de vínculos positivos entre pacientes e seus cuidadores.

O tema empatia apareceu de diferentes maneiras entre os estudantes, em falas relacionadas à situação de se colocar no lugar do paciente, levar carinho, atenção, ter cuidado e delicadeza com o paciente e tratá-lo como gostaria de ser tratado.

Com relação ao trabalho em equipe, a PNH considera-o como um de seus princípios norteadores. O fortalecimento do trabalho em equipe multiprofissional estimula a transdiciplinaridade e a grupalidade. Em nosso estudo a equipe de saúde foi referida como um ponto a conter em um atendimento para que ele seja humanizado, o que pode ser visto na fala da estudante a seguir:

[...] saber que você não trabalha sozinho, você trabalha com um grupo de pessoas e eu acho que humanização também é você saber tratar bem um companheiro seu de serviço [...] (Elda)

A proposta de humanização da assistência à saúde é vista como um valor para a conquista de uma melhor qualidade de atendimento à saúde do usuário e de melhores condições de trabalho para os profissionais.

Neste estudo, com relação ao atendimento prestado pelo estudante de fisioterapia, os usuários e acompanhantes foram unânimes em classifica-lo como positivo, de acordo com os exemplos:

[...] excelente trabalho [...] (Alice) (Amanda) [...] foi bom eu gostei [...] (Ulisses) (Uiara)

Ainda os usuários e acompanhantes caracterizaram $\mathrm{o}$ atendimento relatando $\mathrm{o}$ porque de ele serfoi positivo:

[...] respeitoso, preocupado comigo [...] coloca a gente como prioridade durante o atendimento [...] (Uiara)

O desempenho do profissional de saúde resulta de experiências, da sua cultura e subjetividade ao longo da sua vivência profissional. No presente estudo quando os usuários ou acompanhantes foram abordados sobre se houve diferença entre o atendimento dos estudantes de fisioterapia com o de outro fisioterapeuta com experiência, foi possível observar pelas falas, que o que eles valorizam 
são as atitudes do estudante ou do profissional. Elas devem ser permeadas pelos atributos que consistem em dedicação, cuidado, atenção, educação, diálogo, carinho e acolhimento.

WALDOW 1999 diz que a qualidade da assistência na percepção do usuário está mais associada à humanização do cuidado e às atitudes do profissional. NATIONS E GOMES 2007 corroboram a afirmação de Waldow, ao reconhecerem que a competência humana na óptica do paciente internado é a habilidade mais relevante do profissional de saúde. Saber cuidar da pessoa, não somente da doença é crucial. Competência significa, aqui, ser afetivo, hábil em conversar e incluir o paciente na tomada de decisão. Essas atitudes constituem requisitos fundamentais.

\subsection{Humanização na graduação}

As Diretrizes Nacionais dos Cursos de Graduação na área da saúde, apontam que "a formação do profissional deve contemplar o sistema de saúde vigente no país, a atenção integral da saúde num sistema regionalizado e hierarquizado de referência e contra referência e o trabalho em equipe." (BRASIL, 2001)

Em relação à $\mathrm{PNH}$, "no eixo da educação permanente, indica-se que a $\mathrm{PNH}$ componha o conteúdo profissionalizante na graduação, na pós-graduação e na extensão em saúde vinculando-a aos Polos de Educação Permanente e as instituições formadoras." (BRASIL, 2004). Nas falas dos estudantes entrevistados, entretanto, a inserção da temática da humanização nos currículos é assunto ainda não é muito enfatizado como pode constatar:

[...] tem falado muito pouco de humanização, tem que se abordar mais, nas faculdades quanto em especializações [...] (Edna)

[...] eu não me lembro, mas eu acho que não teve, não foi abordado esse tema com a gente, mas eu acho que seria bom, principalmente para quem vai vir para o hospital [...] (Érica)

Fica claro, também, que alguns estudantes trazem a definição de humanização de uma forma superficial ou ainda relatam não ter conhecimento do que é a humanização:

[...] eu sei muito pouco desse assunto, mas eu acho que é mais ou menos isso mesmo, tratar o paciente como um todo mesmo, sem diferença [...] (Elenice)

[...] tratar com respeito, com dignidade, com ética, não ficar falando do paciente para outros profissionais [...] de igual, como se fosse um familiar meu [...] (Elisa)

Ainda assim consideram importante

para a formação a inserção da temática da humanização no currículo:

[...] porque amanhã você chega para trabalhar [...] a maneira como você atende o paciente, garante seu sucesso [...] (Edite)

Essas falas mostram a carência de informações e de conhecimentos científicos sobre a temática da humanização no período da graduação. Entretanto, pode-se percebe que está latente em cada um deles o respeito pelo ser humano, demonstrando que na graduação pode-se enraizar valores e atitudes de respeito à vida. Então, a instituição formadora deve-se colocar como responsável também por preparar, durante o curso, esses futuros profissionais em uma nova cultura de atendimento à saúde. 


\section{CONSIDERAÇÕES FINAIS}

O tema humanização é amplo e envolve muitos fatores, os quais dentre as políticas de saúde pública, a participação de várias esferas gestoras e governamentais, incluindo trabalhadores e usuários de saúde.

Neste estudo, foi possível constatar que os usuários e acompanhantes veem o atendimento recebido do estudante de fisioterapia com satisfação, tanto pelo saber técnico da profissão, visto que o paciente apresentou evolução clínica, quanto pelos atributos afetivos demonstrados.

A maior dificuldade encontrada pelos estudantes de fisioterapia com relação ao relacionamento com o paciente hospitalizado foi quanto a gravidade do caso.

Os estudantes consideraram o tema humanização importante e fundamental na graduação porque além de ser um conhecimento importante, se torna um diferencial de sucesso para o profissional e garante um atendimento de qualidade.

Finalmente, consideramos que todo aquele que escolhe atuar na área da saúde deve possuir um compromisso com o ser humano, pois sem ele o profissional não é capaz de criar vínculos, ouvir e entender o outro. Bem como, que existe maior chance de se formar um profissional mais humanizado quando a sua educação associa o saber técnico de cada profissão com um enfoque humanitário.

\section{REFERÊNCIAS}

Brasil. Ministério da Saúde. Secretaria de Assistência à Saúde. Programa Nacional de Humanização da Assistência Hospitalar. Brasília (DF): Ministério da Saúde; 2001.

Howard J. Humanization and dehumanization of health care: a conceptual view. In: Howard J.; Strauss A. editors Humanizing health care. New York (NY): John Wiley \& Sons; 1975. p. $57-102$.

Brasil. Ministério da Saúde. Secretaria Executiva. Núcleo Técnico da Política Nacional de Humanização. Humaniza SUS: Política Nacional de Humanização: documento base para gestores e trabalhadores do SUS. Brasília (DF): Ministério da Saúde; 2004.

Sanches E, Marques A. Origem e evolução da fisioterapia: aspectos históricos e legais.

RevFisioterUniv São Paulo. 1994;1(1):5-10.

Brasil. Portaria do GR n. 347, de 7 de abril de 1967. Regulamenta os cursos de fisioterapia, terapia ocupacional e sua organização didática. Diário Oficial da União (DF); 13 abr. 1967; Seção1:13.

Brasil. Presidência da Republica. Lei n. 5540, de 28 de novembro de 1968. Fixa normas de organização e funcionamento do ensino superior e sua articulação com a escola média, e dá outras providências [Internet]. Diário Oficial da União (DF); 23 nov. 1968. [citado 20 nov 2013]. Disponível em: http://www.planalto.gov.br/ccivil_03/leis/1554 $\underline{0 . h t m}$

Brasil. Ministério da Educação, Conselho Nacional de Educação, Câmara de Educação Superior. Resolução n.1210, de 7 de dezembro de 2001. Institui Diretrizes Curriculares Nacionais do Curso de Graduação em Fisioterapia, Fonoaudiologia e Terapia Ocupacional. Diário Oficial da União, Brasília (DF); 10 dez 2001; Seção 1:22. 
Gomes R. Análise e interpretação de dados de pesquisa qualitativa. In: Deslandes SF, Minayo CS. Pesquisa social: teoria, método e criatividade. Petrópolis (RJ): Vozes; 2009.

Brasil. Ministério da Saúde. Secretaria Executiva. Núcleo Técnico da Política Nacional de Humanização. HumanizaSUS: Política Nacional de Humanização: a humanização como eixo norteador das prática de atenção e gestão em todas as instâncias do SUS. Brasília (DF): Ministério da Saúde; 2004.

Nations MK, Gomes AMA. Cuidado, "cavalo batizado" e crítica da conduta profissional pelo paciente-cidadão hospitalizado no Nordeste brasileiro. Cad Saúde Pública. 2007;23(9):2103-12.

Brasil. Ministério da Saúde.Política Nacional de Humanização da Atenção e da Gestão do SUS: Material de Apoio. $3^{\mathrm{a}}$ ed. Brasília (DF): Ministério da Saúde; 2006.

Caetano VC, Cruz DT, Silva GA, Leite ICG. O lugar ocupado ela assistência fisioterapêutica: representações sociais d trabalhadores com DORT. Fisioter mov. 2012;25(4):767-776.

Houaiss A, Villar MS, Franco FMM.

Dicionário Houaiss da língua portuguesa: com a nova ortografia da língua portuguesa. Rio de Janeiro (RJ): Objetiva; 2009. Respeito; p. 1653.

Fernandes MFP, Pereira RCB. Percepção do professor sobre respeito. Nursing. 2005;87(8):375-9.

Pessini L. Humanização da dor e sofrimento humanos no contexto hospitalar. Rev

Bioética. 2002;10(2):51.

Pessini L, Bertachini L. Humanização e cuidados paliatvos. São Paulo (SP):Loyola; 2004.
Waldow V. Cuidado humano: o resgate necessário. $2^{\mathrm{a}}$ ed. Porto Alegre (RS): Sagra Luzzatto; 1999.

Merhy EE. O ato de governar as tensões constitutivas do agir em saúde como desafio permanente de algumas estratégias gerenciais. Ciênc Saúde Coletiva. 1999; 4(2):305-314. Nogueira-Martins, MCF. Humanização das relações assistenciais: a formação do profissional de saúde. São Paulo: casa do Psicólogo, 2004. 